\title{
INFLUÊNCIA DO ESPAÇAMENTO NO DIÂMETRO E ALTURA DE TRÊS CLONES DE EUCALIPTO
}

\author{
Frederico de Assis Leal ${ }^{1}$ \\ Ingrid Martins Soares ${ }^{2}$ \\ Thelma Shirlen Soares ${ }^{3}$
}

\begin{abstract}
Resumo: Este estudo analisou a dinâmica de crescimento inicial de um povoamento de Eucalipto implantado no delineamento experimental em blocos casualizados com parcelas subdivididas, com três repetições, do $5^{\circ}$ ao $41^{\circ}$ mês. Nas parcelas foram avaliados os espaçamentos de plantio ( $3 \times 2 \mathrm{~m}$ e $3 \times 3$ m) e nas subparcelas os clones (3335, 3336 e 3487). Foram analisadas as variáveis diâmetro a 1,30 m de altura do solo (DAP) e altura total (HT). Verificou-se que não houve diferença significativa no crescimento em DAP e HT para os três clones estudados, porém houve diferença significativa entre os espaçamentos apenas para a variável DAP. Não houve interação entre clones e espaçamentos no período de crescimento estudado. Com base no diâmetro médio das árvores, conclui-se que o espaçamento mais indicado é o 3,0 $x$ 3,0 m.
\end{abstract}

Palavras-chave: Densidade de plantio; arranjos espaciais; teste clonal.

\footnotetext{
1 Universidade Federal de Goiás - Regional Jataí, Cx Postal 3, 75801-615, Jataí - Go, lealfrederico@hotmail.com.

2 Universidade Federal de Goiás - Regional Jataí, Cx Postal 3, 75801-615, Jataí - GO, ingridms17@hotmail.com

${ }^{3}$ Universidade Federal de Goiás - Regional Jataí, Cx Postal 3, 75801-615, Jataí - GO, thelmasoares@ufg.br.
} 